\title{
Without Explicit Targets, Does France Meet Minimum Volume Thresholds for Hip and Knee Replacement and Bariatric Surgeries?
}

\author{
William B. Weeks ${ }^{1,2,3^{*}}$, Bruno Ventelou ${ }^{3}$, Zeynep Or ${ }^{4}$
}

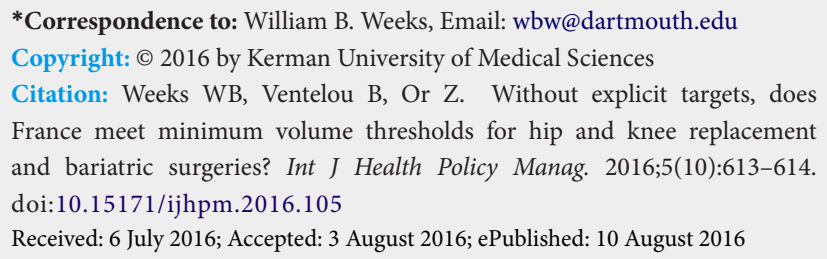

\section{Dear Editor,}

Persistent findings of a relationship between higher volumes of surgical care and better outcomes ${ }^{1}$ have caused 3 large US healthcare systems to refer surgical cases when they do not meet minimum volume thresholds for bariatric surgery (where the minimum threshold is 40 surgeries per year) and total hip or total knee replacement surgeries (where it is 50 surgeries per year). ${ }^{2}$

In France, minimum surgical volumes for complex cardiac surgeries and cancer surgeries have been in place since $2006^{3}$; however, minimum threshold volumes are not in place for bariatric surgery or for hip or knee replacement surgeries. We sought to determine the proportion of cases that occur in French hospitals that did not meet the US minimum volume thresholds for these 3 surgical procedures in 2012 and 2013. To do this, from the Agence Technique de l'Information sur l'Hospitalisation, ${ }^{4}$ we obtained individual case-level data on all surgical discharges from hospitals in mainland France and Corsica for 2012 and 2013. Data included the primary International Classification of Diseases (ICD-10) admission diagnosis, surgical procedures completed during the stay (identified by Classification Commune des Actes Médicaux [CCAM] $\operatorname{codes}^{5}$ ), and the unique hospital identification number where the admission took place. We based our criteria for identifying relevant admissions on definitions used by the aforementioned US healthcare systems to effectuate minimum volume thresholds, and we translated ICD-9 codes and current procedural technology (CPT) codes to CCAM codes (Table, top).

To determine the annual volume of each procedure completed at individual hospitals, we aggregated cases on hospital identifier. We then applied the appropriate minimum volume threshold and calculated the number and proportion of procedures completed in hospitals that met minimum volume thresholds as well as the number and proportion of hospitals that did and did not meet minimum volume standards. We found that more than $90 \%$ of all 3 surgical interventions examined were performed in hospitals that met US minimum volume standards (Table, bottom). Between 2012 and 2013, the number of hospitals performing each procedure as well as the number that met the minimum volume thresholds increased for each procedure; however, the proportion of hospitals that met minimum volume standards fell slightly for hip replacement surgery.

In the absence of specific minimum volume thresholds, we found that the vast majority of patients obtained care in French hospitals that adhered to such thresholds for 3 common and increasingly used surgical procedures. We found evidence of market consolidation for 2 procedures where the proportion of hospitals that met minimum volume standards were relatively low, but stagnation of market consolidation when the proportion of hospitals that met minimum volume standards was relatively high.

Two factors might explain our findings. First, France has long had imposed minimum volume standards for other procedures; the market might be anticipating implementation of standards for the procedures we examined. Second, French policy-makers have encouraged competition in the hospital sector; to reduce expenditures and stay competitive in the face of declining revenues, hospitals may focus on high volume procedures, so that the very high fixed costs that they experience can be spread across a larger number of procedures. $^{6}$

Our analysis suggests that, in the absence of direct policy, these factors might have spillover effects that lead to broader adherence to minimum volume standards. While our findings suggest that there may be an upper limit to the proportion of hospitals that adhere to such standards, the additional costs and aggravation expended in monitoring adherence to minimum volume standards may not be warranted given the very small proportion of patients that might be impacted by such efforts. France's long-term efforts to develop a surgical culture that appreciates volume-outcomes relationships appears to have spillover effects and generate positive externalities for patients who need other surgical procedures.

\section{Acknowledgments}

WBW was funded by a Fulbright-Tocqueville grant through the Franco-American Commission for Educational Exchange and by the Institute of Advanced Studies at Aix-Marseille University, Marseille, France.

Ethical issues

Not applicable. 
Table. For 3 Procedures, the Total Number of Procedures, the Number and Proportion Completed in Hospitals That Met Minimum Volume Thresholds, the Number of Hospitals in Which the Procedure Was Performed, and the Number and Proportion of Hospitals That Met Minimum Volume Thresholds in 2012 and 2013

\begin{tabular}{|c|c|c|c|c|c|c|c|c|c|}
\hline \multicolumn{10}{|l|}{ Procedure Definition } \\
\hline & \multicolumn{3}{|c|}{ Bariatric Surgery } & \multicolumn{3}{|c|}{ Knee Replacement Surgery } & \multicolumn{3}{|c|}{ Hip Replacement Surgery } \\
\hline Minimum annual volume threshold & \multicolumn{3}{|l|}{40} & \multicolumn{3}{|l|}{50} & \multicolumn{3}{|l|}{50} \\
\hline ICD 9 codes used in the United States & \multicolumn{3}{|c|}{278.00 or 278.01} & \multicolumn{3}{|c|}{$715 . x x$ or $733.4 x$} & \multicolumn{3}{|l|}{$733.4 x$} \\
\hline CPT Codes used in the United States & \multicolumn{3}{|c|}{$\begin{array}{l}43644,43775,43659,43846 \\
43847,43848\end{array}$} & \multicolumn{3}{|c|}{$\begin{array}{l}27130,27134,27137,27138 \\
27299\end{array}$} & \multicolumn{3}{|l|}{27487} \\
\hline ICD 10 diagnostic criteria equivalents & \multicolumn{3}{|l|}{ E66.X } & \multicolumn{3}{|c|}{ M16.X or M87 } & \multicolumn{3}{|l|}{ M87 } \\
\hline $\begin{array}{l}\text { Classification Commune des Actes } \\
\text { Médicaux codes equivalents }\end{array}$ & \multicolumn{3}{|c|}{$\begin{array}{l}\text { HFCA001, HFCC003, HFCC004, } \\
\text { HFFA001, HFFA011, HFFC004, } \\
\text { HFFC018, HFGC900, HFKA001-2, } \\
\text { HFKC001, HFLC900, HFLE001, } \\
\text { HFMA009-11, HFMC006-9, } \\
\text { HGCC027 }\end{array}$} & \multicolumn{3}{|c|}{$\begin{array}{l}\text { NEKA010-022, NEMA018, } \\
\text { NEMA020 }\end{array}$} & \multicolumn{3}{|c|}{ NFKA006-009 } \\
\hline \multicolumn{10}{|l|}{ Analytic Results } \\
\hline Year & 2012 & 2013 & $\begin{array}{l}\text { Annual } \\
\text { Growth }\end{array}$ & 2012 & 2013 & $\begin{array}{l}\text { Annual } \\
\text { Growth }\end{array}$ & 2012 & 2013 & $\begin{array}{l}\text { Annual } \\
\text { Growth }\end{array}$ \\
\hline Total number of procedures & 45161 & 50354 & $11 \%$ & 86236 & 93873 & $9 \%$ & 144473 & 153494 & $6 \%$ \\
\hline $\begin{array}{l}\text { Number completed in hospitals that } \\
\text { met minimum volume thresholds }\end{array}$ & 42690 & 47692 & $12 \%$ & 79485 & 87047 & $10 \%$ & 141692 & 151039 & $7 \%$ \\
\hline $\begin{array}{l}\text { Proportion completed in hospitals that } \\
\text { met minimum volume thresholds }\end{array}$ & $94.5 \%$ & $94.7 \%$ & & $92.2 \%$ & $92.7 \%$ & & $98.1 \%$ & $98.4 \%$ & \\
\hline $\begin{array}{l}\text { Total number of hospitals in which the } \\
\text { procedure was performed }\end{array}$ & 515 & 522 & $1 \%$ & 793 & 800 & $1 \%$ & 820 & 835 & $2 \%$ \\
\hline $\begin{array}{l}\text { Number of hospitals that met minimum } \\
\text { volume thresholds }\end{array}$ & 273 & 287 & $5 \%$ & 493 & 511 & $4 \%$ & 701 & 711 & $1 \%$ \\
\hline $\begin{array}{l}\text { Proportion of hospitals meeting } \\
\text { minimum volume thresholds }\end{array}$ & $53.0 \%$ & $55.0 \%$ & & $62.2 \%$ & $63.9 \%$ & & $85.5 \%$ & $85.1 \%$ & \\
\hline
\end{tabular}

Abbreviations: ICD, International Classification of Diseases (ICD); CPT, current procedural technology.

\section{Competing interests}

Authors declare that they have no competing interests.

\section{Authors' contributions}

Conception and design (WBW, BV, ZO); Acquisition of data (WBW, BV, ZO); Analysis and interpretation of data (WBW, BV, ZO); Drafting of the manuscript (WBW); Critical revision of the manuscript for important intellectual content (BV, ZO); Statistical analysis (WBW).

\section{Authors' affiliations}

${ }^{1}$ The Dartmouth Institute for Health Policy and Clinical Practice, Dartmouth College, Hanover, NH, USA. ${ }^{2}$ The Geisel School of Medicine, Hanover, NH, USA. ${ }^{3}$ Aix-Marseille School of Economics (CNRS \& EHESS), Aix-Marseille University, Marseille, France. ${ }^{4}$ Institut de recherché et documentation en économie de la santé, Paris, France.

\section{References}

1. Reames BN, Ghaferi AA, Birkmeyer JD, Dimick JB. Hospital volume and operative mortality in the modern era. Ann Surg. 2014;260(2):244-251. doi:10.1097/sla.0000000000000375
2. Sternberg S. Hospitals move to limit low-volume surgeries. US News and World Report. http://www.usnews.com/news/ articles/2015/05/19/hospitals-move-to-limit-low-volumesurgeries.

3. Com-Ruelle L, Or Z, Renaud T. The volume-outcomes relationship in hospitals: lessons from the literature. http://www. irdes.fr/EspaceAnglais/Publications/IrdesPublications/QES135. pdf. IRDES (The Institute for Research and Information in Health Economics); 2008.

4. ATIH. Agence Technique de I'Information sur l'Hospitalisation. http://www.atih.sante.fr/echelle-nationale-de-couts-par-ghm. Accessed March 8, 2016.

5. Classification Commune des Actes Médicaux (CCAM). http:// www.ameli.fr/accueil-de-la-ccam/index.php. Accessed March 8, 2016.

6. Rauh SS, Wadsworth E, Weeks WB, Weinstein JN. The savings illusion: why quality improvement fails to deliver bottom-line results. New Engl J Med. 2011;365(26):e48. doi:10.1056/ NEJMp1111662. 